Article

\title{
Trend Analysis of Water Poverty Index for Assessment of Water Stress and Water Management Polices: A Case Study in the Hexi Corridor, China
}

\author{
Shan Huang ${ }^{1,2}$, Qi Feng ${ }^{1, *}$, Zhixiang Lu ${ }^{1}$, Xiaohu Wen ${ }^{1}$ and Ravinesh C. Deo ${ }^{1,3}$ \\ 1 Key Laboratory of Ecohydrology of Inland River Basin, Northwest Institute of Eco-Environment and \\ Resources, Chinese Academy of Sciences (CAS), Lanzhou 730000, China; huangshan@lzb.ac.cn (S.H.); \\ lzhxiang@lzb.ac.cn (Z.L.); xhwen@lzb.ac.cn (X.W.); Ravinesh.Deo@usq.edu.au (R.C.D.) \\ 2 University of Chinese Academy of Sciences, Beijing 100049, China \\ 3 School of Agricultural, Computational and Environmental Sciences, International Centre for Applied \\ Climate Sciences (ICACS), Institute of Agriculture and Environment (IAg \& E), University of Southern \\ Queensland, Springfield QLD 4300, Australia \\ * Correspondence: qifeng@lzb.ac.cn; Tel.: +86-931-496-7089
}

Academic Editor: Vincenzo Torretta

Received: 15 February 2017; Accepted: 3 May 2017; Published: 5 May 2017

\begin{abstract}
The Hexi Corridor, an important part of the Silk Road Economic Belt, is considered the poorest, most water scarce, and most ecologically fragile area in China. Establishing efficient strategies for water management in an integrated manner is utterly important. This paper evaluates the spatio-temporal trends of water stress (2003-2015) in the Shule (SLRB), Heihe (HHRB), and Shiyang (SYRB) River Basins in the Hexi Corridor based on the Water Poverty Index (WPI). For SLRB, the WPI ranged from 55.3 to 66.4 , followed by HHRB (40.1-58.2) and SYRB with WPI $=20.0-43.9$. Both SYRB and HHRB showed an improvement in the water situation based on increasing trends, whereas SLRB demonstrated a small decrease. The effectiveness of water policy interventions was evident in SYRB and HHRB, standing at odds with SLRB where interventions required adjustment to ameliorate the water stress. For the start and end years, pentagrams for five components (Resource, Access, Capacity, Use, Environment) demonstrated the merits and weaknesses of WPI as a comparative framework for assessing the water situation. This study also reaffirms the importance of WPI, utilized for investigating the efficacy of implemented water policies and benchmarking the future priorities in basins not only in China but also in other locations where water resources management is a key issue.
\end{abstract}

Keywords: water poverty index; water stress; water resources management; spatio-temporal changes; Hexi Corridor of China

\section{Introduction}

Water is a vital resource for natural ecosystems and for sustainable human life [1], especially in arid and semi-arid regions. Water and poverty are inextricably related through the following aspects [2]: water for basic services, food production, job creation, sustainable environmental management, and for water rights and entitlements for poorer people. Wilk et al. [3] suggested that a better understanding of poverty and prosperity is imperative to enforce strategic actions for the efficient management of water resources. Water plans and management can offer cost-competitive adaptation to sustainable development with the potential to meet both short and medium term targets for reducing water scarcity risks [4]. Many researchers agree on a set of specific strategies that can help with an increase in water use efficiency, improve the environment, and maintain sustainable water services in rural populations [5]. An innovative approach to integrating the inter-playing components of human water 
use with the relevant water management strategies is an essential tenet for core decision-making and for various policies devised on water poverty and the sustainable utilization of water resources [6,7].

The Hexi Corridor, exemplified as the study region, which is also an important sector of the Silk Road and the New Asia-European Railway, is considered to be a poor and a limited water resource area. Melt water and groundwater being the two primary water resources, the Hexi Corridor tends to suffer from significant periods of water deficits, leading to a recession of the groundwater and a deterioration of the eco-environments along with the persistent poverty that has been reported over the last decade. Due to the importance of this region in contemporary China, significant efforts have been expended by national and local government agencies to devise sustainable plans such as those listed in Table 1.

Table 1. Name, objective, executive period, investment, and measures of policy implemented in the Shule (SLRB), Heihe (HHRB), and Shiyang (SYRB) River Basins within the Hexi Corridor.

\begin{tabular}{|c|c|c|}
\hline Study Basin & $\begin{array}{l}\text { Name of Policy/Objective/Executive } \\
\text { Period/Investment (Million US \$) }\end{array}$ & Measures \\
\hline SLRB & $\begin{array}{l}\text { Comprehensive Development Project of Agriculture } \\
\text { Irrigation and Inhabitant Resettlement in Shule River } \\
\text { Basin: Empowered } 7.5 \times 10^{4} \text { peasantry in central and } \\
\text { western Gansu Province to SLRB to eliminate poor } \\
\text { living conditions from } 1996 \text { to } 2006 ; 295.1\end{array}$ & $\begin{array}{l}\text { Inhabitant resettlement; Water infrastructure; } \\
\text { Sustainable agricultural and economic } \\
\text { developmental. }\end{array}$ \\
\hline HHRB & $\begin{array}{l}\text { Building a Water-saving Society in Zhangye: (hold 91\% } \\
\text { of population and } 95 \% \text { of croplands of HHRB) } \\
\text { Improve the carry capacity of water resources to } \\
\text { achieve the win-win goal of ecological water transfer } \\
\text { and regional development in HHRB; from } 2002 \text { to } 2005\end{array}$ & $\begin{array}{l}\text { Reform of water rights system; Control the } \\
\text { total water resources; Readjust the industrial } \\
\text { structures; Water-saving transformation in } \\
\text { irrigation district. }\end{array}$ \\
\hline SYRB & $\begin{array}{l}\text { Grain for green project in Minqin: Improve the } \\
\text { ecological environment and maintain the survival and } \\
\text { development of local area; from } 2002 \text { to } 2013\end{array}$ & $\begin{array}{l}\text { Convert cropland to forest and grassland; } \\
\text { Afforest on waste land. }\end{array}$ \\
\hline
\end{tabular}

Notes: The primary measures of polices in the study basins can be measured practically by the five components of the Water Poverty Index. The data were acquired from public government documents available on the Internet. Some policies do not show the amount of investment as they are executive orders or not available publically. 1 US $\$=6.68$ RMB.

By the year 2015, some of these projects and plans were already implemented, while the others were still pending. This clearly reflects a concern regarding the water stress situation and the related poverty within the Hexi Corridor. One may therefore ask: how successful are the proposed measures for reducing the water scarcity and the defined new water and developmental policies? There is no doubt that an assessment of the progress, determination of the priority developmental activities, and the design of management strategies for the water resource sector are very complex. Considering this, an interdisciplinary approach utilized in an integrated manner needs to be adopted to help 
analyze such situations [8-11]. Water use indicators are thus considered to be powerful quantitative tools for decision-making [12].

In order to devise a standardized mechanism for assessing the water stress, several water availability indices have been developed in this paper. One primary index, is the Water Poverty Index (WPI) [13] that aims to foster a strategic approach for understanding the complexities associated with water issues by integrating physical, social, economic, and environmental aspects and also linking the water stress to the related poverty in the respective region $[14,15]$. In its various forms, the WPI has broadly been used to manage water resources to ensure a sustainable future [16]. Precisely, the WPI has been applied in many research works; for example, from the viewpoint of community to local perspectives $[14,17,18]$, regional and basin levels [11,19-23], and national and international perspectives [8-10,24]. In most of these studies, the WPI has been classified into five major components: water resources, water access, use, capacity (social and economic), and water-related environmental quality. These sub-components can provide an aggregated picture of the water resource situation in respective study areas. The aggregated scores can provide key decision-makers with a clear and comprehendible performance indicator applied for monitoring the water stress situation and for identifying and selecting areas of greatest need, particularly for resource allocation and developmental prioritization [11]. Accordingly, the application of this index shows that if the WPI can be computed at a reasonable time interval, it could be utilized to monitor the developmental progress within the respective region [14]. In view of its practical importance, the WPI has attracted considerable research attention from policymakers, development agencies, and government professionals working in water resources management $[8,9,11,17,18,21]$. However, in the context of the basins studied within the Hexi Corridor (China) considered in this paper, the utility of the WPI for decision-making is yet to be investigated.

The novelty of this paper is to apply for the first time within the Hexi Corridor, the Water Poverty Index (WPI) to enable an assessment of the water poverty situation and to study the spatio-temporal changes in the three inland river basins (Shule, Heihe, and Shiyang River Basins). The results can serve as a reference used to generate a knowledge base for water poverty and watershed analysis; playing a vital role in a fair, equitable, and transparent decision-making and including the prioritization of policy interventions. The precise aims of this paper are threefold: (1) to provide a comprehensive overview of water management challenges in accordance with WPI based on five important components (i.e., Resource, Access, Use, Capacity, and Environment) and the related subcomponents to establish an index-based system; (2) assess the effectiveness of previous plans implemented for water use in terms of the temporal changes in WPI; (3) to investigate the trends in WPI from 2003 to 2015. This paper is structured as follows: Section 2 details the study area and methodological overview, framework, and calculation of WPI. Section 3 presents the results, including temporal changes of the components, water poverty situational assessments and a detailed analysis and visualization between 2003 and 2015. Section 4 outlines the discussion, and Section 5 concludes the findings of the paper and provides some points for further research.

\section{Materials and Methods}

\subsection{Study Area}

In this paper, we validate the usefulness of the Water Poverty Index (WPI) applied in the Hexi Corridor of China $\left(92^{\circ} 21^{\prime}\right.$ to $104^{\circ} 45^{\prime} \mathrm{E}, 37^{\circ} 15^{\prime}$ to $\left.41^{\circ} 30^{\prime} \mathrm{N}\right)$, located in northwest of the Gansu Province. The region starts on the Tibetan Plateau and ends in the grassland of Inner Mongolia, in desert land from the south to the north, in Wushaoling Mountains in the east, and in Yumenguan in the west. The Hexi Corridor is a long narrow corridor, covering a distance of 40-100 km from the north to the south and stretching about $1120 \mathrm{~km}$ from the east to the west, with an area of $27.6 \times 10^{4} \mathrm{~km}^{2}$. It covers about $60 \%$ of the territory, and it is inhabited by almost $20 \%$ of the population in the Gansu province. In terms of its climatic conditions, the region has an arid continental climate with an annual rainfall 
reaching no more than $200 \mathrm{~mm}$, whereas the annual evaporation falls between 1500 and $3200 \mathrm{~mm}$. However the melting snow from mountains, fertile oases, and annual sunshine duration amounts to 2800-3300 hours, making the Hexi Corridor quite attractive for the development of irrigation-based agriculture. Consequently, this area is an important commodity grain base of the northwest region of China.

In the Hexi Corridor, there are three independent landlocked river systems; the Shule River Basin (SLRB), the Heihe River Basin (HHRB), and the Shiyang River Basin (SYRB), as illustrated in Figure 1. Water resources are generated in the mountains of the upper reach, but these are mostly utilized and consumed in the middle reaches and lower reaches of the river system. The basins are characterized by scarce precipitation, poverty, high proportion of agricultural water use (accounting for more than $80 \%$ of the water consumption), poor water resources management, and ecological insecurity, although the regions considered exhibit different ranges of these characteristics (Table 2). For example, the SLRB, with the largest area $\left(169,983 \mathrm{~km}^{2}\right)$, encompasses the smallest population $\left(50.4 \times 10^{4}\right.$ people), whereas the SYRB has the highest population density in spite of having the smallest area $\left(40,687 \mathrm{~km}^{2}\right)$. The groundwater contributions to the water budget in these regions for the year 2015 were about $21.9 \%, 27.0 \%$, and 32.4\% respectively in SLRB, HHRB, and SYRB. The utilization of water resources in the SLRB, SYRB, and HHRB reached about $76 \%, 138 \%$, and $146 \%$, respectively, in 2015 , which is higher than the $40 \%$ recognized as an internationally acceptable maximum threshold. As a consequence, a number of water-related, eco-environmental, and socio-economic challenges have emerged in the Hexi Corridor, which are particularly pronounced for SYRB.

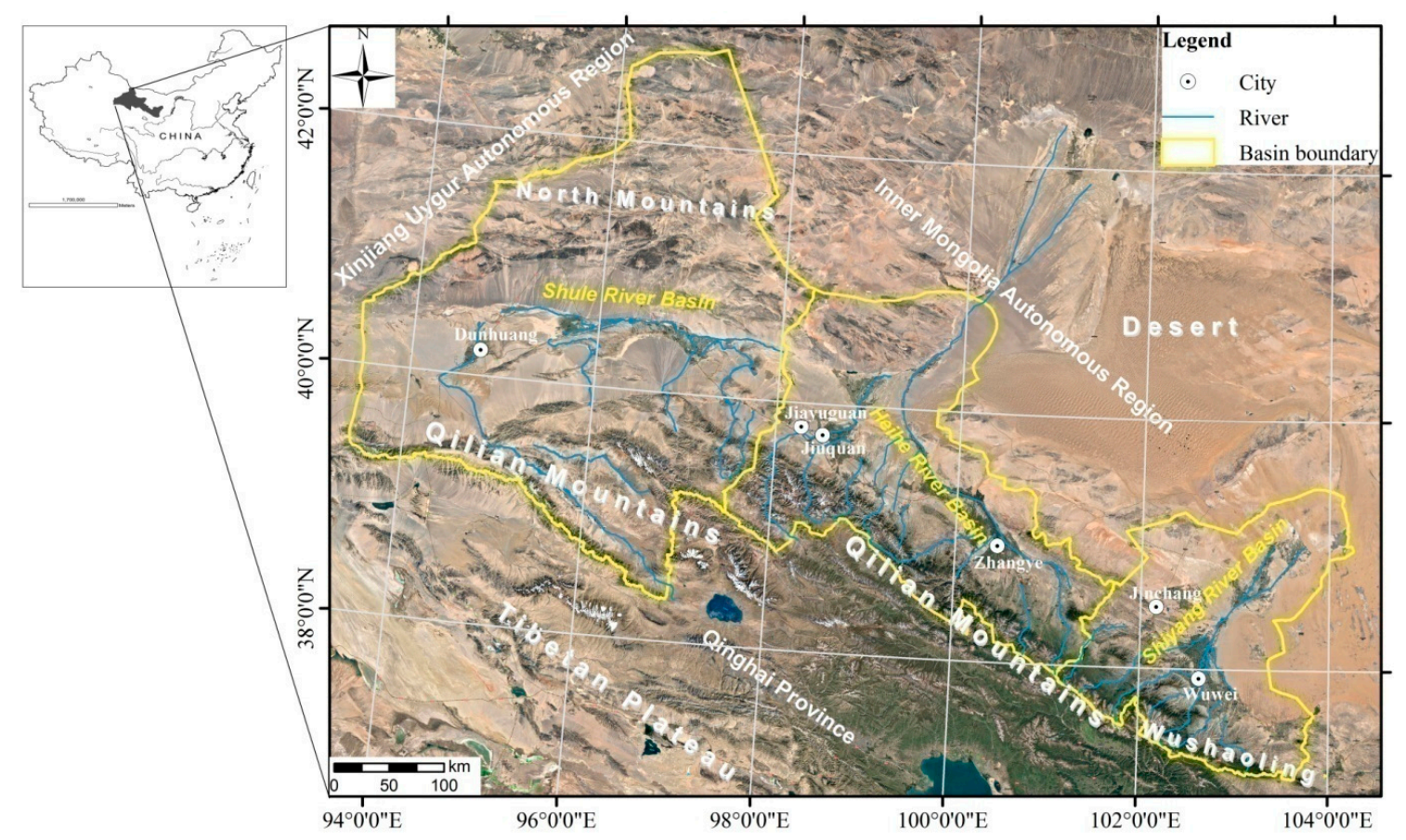

Figure 1. Location of the three river basins in the Hexi Corridor, China.

Table 2. Area, population, water resources, and use in the three basins.

\begin{tabular}{cccccc}
\hline Basin & Area $\left.\mathbf{( k m}^{\mathbf{2}}\right)$ & $\begin{array}{c}\text { Population } \\
\left(\mathbf{1 0 ^ { 4 }} \text { Person) }\right.\end{array}$ & $\begin{array}{c}\text { Groundwater Contributions } \\
\text { to Water Budget (\%) }\end{array}$ & $\begin{array}{c}\text { Ratio of Irrigation } \\
\text { Water (\%) }\end{array}$ & $\begin{array}{c}\text { Water Use } \\
\text { Intensity (\%) }\end{array}$ \\
\hline SLRB & 169,983 & 50.4 & 21.9 & 82.3 & 76 \\
HHRB & 59,354 & 198.7 & 27.0 & 83.6 & 138 \\
SYRB & 40,687 & 223.2 & 32.4 & 85.3 & 146 \\
\hline
\end{tabular}




\subsection{Water Poverty Index (WPI)}

In this paper, we apply the Water Poverty Index (WPI), which has been tested in a plethora of studies elsewhere, and capture a comprehensive overview of water management challenges in different study regions (e.g., $[10,13,16,17,25-27])$. To apply WPI in the Hexi corridor and to investigate the water poverty situation, five components of water management are considered (i.e., resources, access, capacity, use, and environment).

Resources-this component measures the physical availability of water resources, which encompasses natural precipitation as a primary source for water and surface water and groundwater as secondary yet unequivocally important sources;

Access - this component measures how well provisioned the population currently is, including the infrastructural conditions of domestic, irrigation, and industrial water usage;

Capacity - this component refers to the social and economic capacity to practically utilize and manage water resources;

Use-this component includes an estimated level of water usage by different sectors of the economy, including an assessment of the efficiency of how water resources are utilized;

Environment- this component is adopted for an evaluation of environmental integrity related to environmental impacts in the process of water utilization and management.

Since these components are somewhat broadly represented, it is reasonable to consider that each should be partitioned into different sub-components to establish an index system. Mathematically, this is written as:

$$
\mathrm{WPI}=\frac{\mathrm{wrR}+\mathrm{waA}+\mathrm{wcC}+\mathrm{wuU}+\mathrm{weE}}{\mathrm{wr}+\mathrm{wa}+\mathrm{wc}+\mathrm{wu}+\mathrm{we}}
$$

In Equation (1), WPI refers to the total water poverty score developed for the study areas; wrR, waA, wcC, wuU, and weE are the scores for the components denoted as Resources, Access, Capacity, Use, and Environment, respectivelyl and ' $w r$, wa, wc, wu, and we' are the respective weights for each component of the WPI, applied to designate the importance of each variable used to develop the Water Poverty Index.

According to the weighted values assigned to each sub-component, there are two possibilities for calculating the WPI. The first one accords to the balance methodology utilizing equal weighted values given to the sub-components and the components of WPI in order to avoid issues of subjectivity [16]. This method also ensures that the index is transparent for decision-makers and other stakeholders and that it is one that is comparable among the different basins [11]. This method is usually applied on large scales (i.e., $[9,11,19,20,28])$. The second approach is the unbalanced methodology wherein unequal weighted values are given on the basis of the importance of the variables in water resources management. This is normally applied on a small scale [20]. In this study, the balanced methodology has been adopted to calculate the WPI so that the weighted values of each component were set to 1 . This approach yields a mathematical formula of the form:

$$
\mathrm{WPI}=\frac{\mathrm{R}+\mathrm{A}+\mathrm{C}+\mathrm{U}+\mathrm{E}}{5}
$$

It is imperative to note that each of the five components constitutes the sub-components, which are normalized and bounded by $[0,100]$. Consequently, WPI $=0$ represents the worst (an extreme case of water poverty), while WPI $=100$ is taken to be the best water situation in the respective regions where various data components were analyzed.

\subsection{Selection and Normalization of WPI}

In this paper, the indicators of the water situation and their sub-components were selected after a careful review of the published literature $[10,14,17,19-22,24,28-32]$ and the primary measures of polices applied in the study area. These measures (shown in Table 1) were selected as they are expected to moderate the changes in water resource utilization, population, cultivated land, irrigation facilities, 
farmer livelihood, and eco-environment within the study basins. Importantly, these changes can be suitably reflected by the five components of WPI. We thus applied these indicators to the study area to assess their ability to effectively represent issues of water resource management. An application of the approach resulted in a total of 12 subcomponents, which were derived with the 15 indicators collected from the Water Resources Bulletin of Gansu Province for the study period 2003-2015. Table 3 shows the structure of the WPI with the respective sub-components, indicators of water stress, and the calculation of different sub-components. All these data considered for the development of the WPI were available at the selected basin level.

In order to enhance the portability of the index and its potential application in the present study region, procedures such as a comparison, aggregation, interpretation, and alterations were made to normalize the sub-components into a uniform and a unidirectional scale using a set of thresholds. Sub-components were normalized using the min-max approach [11]. If the increase in sub-components resulted in a better water situation (i.e., R2, A1, etc.), then Equation (3) was applied; otherwise, Equation (4) was applied, viz. U1, E1, and E2. In addition to these, R1 and C1 were normalized by a specific formula in accordance with other research works [11,21,23], as outlined in Table 3.

$$
\begin{aligned}
y_{i j} & =\frac{x_{i j}-\min x_{i j}}{\max x_{i j}-\min x_{i j}} \\
y_{i j} & =\frac{\max x_{i j}-x_{i j}}{\max x_{i j}-\min x_{i j}}
\end{aligned}
$$

In Equations (3) and (4), $y_{i j}$ is the normalization value; $x_{i j}$ is the original value for a basin; and the minimum and maximum refer to the values of all the study basins considered.

In order to avoid the problems associated with boundary values $[0,1]$, the maximum and minimum values should be usually adjusted. According to Heidecke [15], the minimum values were divided by 1.05 and the maximum values were multiplied by 1.05 to enhance the authenticity of the results, as shown in Equations (5) and (6).

$$
\begin{aligned}
Y_{i j} & =\frac{x_{i j}-\min x_{i j} / 1.05}{1.05 \max x_{i j}-\min x_{i j} / 1.05} \\
Y_{i j} & =\frac{1.05 \max x_{i j}-x_{i j}}{1.05 \max x_{i j}-\min x_{i j} / 1.05}
\end{aligned}
$$

After getting the normalization values of subcomponents, the value of each component $\left(C_{i j}\right)$ was computed using Equation (7) such that the WPI was generated via Equation (8). This concurred with the physical interpretations of Equation (2):

$$
\begin{gathered}
C_{i j}=\frac{\sum 100 Y_{i j}}{n} \\
\mathrm{WPI}=\frac{\sum C_{i j}}{5}
\end{gathered}
$$


Table 3. Structure of Water Poverty Index (WPI), subcomponents calculation, and indicators applied in the basins.

\begin{tabular}{|c|c|c|c|}
\hline Components & Subcomponents/Unit & Indicators & Subcomponents Calculation \\
\hline Resources (R) & $\begin{array}{l}\text { R1: Per capita water availability }\left(\mathrm{m}^{3} / \mathrm{yr}\right) \\
\text { R2: Per ha water availability }\left(\mathrm{m}^{3} / \mathrm{ha} / \mathrm{yr}\right)\end{array}$ & \multirow{5}{*}{$\begin{array}{l}\text { a: water availability } \\
\text { b: population } \\
\text { c: cultivated land } \\
\text { d: year-end reservoir water storage } \\
\text { e: annual runoff } \\
\text { f: effective irrigation area } \\
\text { g: water-saving irrigation area } \\
\text { h: actual irrigation area } \\
\text { i: irrigation water consumption } \\
\text { j: industrial water consumption } \\
\text { k: total water supply } \\
\text { l: GDP } \\
\text { m: grain yield } \\
\text { n: annual wastewater discharge } \\
\text { o: groundwater supply }\end{array}$} & $\begin{array}{c}\mathrm{R} 1=\mathrm{a} / \mathrm{b} Y_{R 1}=\frac{x_{i j}-500}{1700-500} \\
\text { if } x_{i j}>1700, Y_{R 1}=1 \\
\text { if } x_{i j}<500, Y_{R 1}=0 \\
\mathrm{R} 2=\mathrm{a} / \mathrm{c}\end{array}$ \\
\hline Access (A) & $\begin{array}{l}\text { A1: \% year-end reservoir water storage } \\
\text { A2: \% irrigation of cultivated land } \\
\text { A3: \% water-saving irrigation area }\end{array}$ & & $\begin{array}{l}\mathrm{A} 1=\mathrm{d} / \mathrm{e} \\
\mathrm{A} 2=\mathrm{f} / \mathrm{c} \\
\mathrm{A} 3=\mathrm{g} / \mathrm{h}\end{array}$ \\
\hline Capacity (C) & C1: per capita GDP ( $\$ /$ person) & & $\begin{array}{c}\mathrm{C} 1=1 / \mathrm{b} \\
Y_{\mathrm{C} 1}=\frac{\log x_{i j}-\log (\min )}{\log (\max )-\log (\min )} \\
\min =\$ 100, \max =\$ 40,000 ;\end{array}$ \\
\hline Use (U) & $\begin{array}{l}\text { U1: \% irrigation water consumption } \\
\text { U2: \% industrial water consumption } \\
\text { U3: output value of per } \mathrm{m}^{3} \text { of water }\left(\$ / \mathrm{m}^{3}\right) \\
\text { U4: grain yield of per } \mathrm{m}^{3} \text { of water }\left(\mathrm{kg} / \mathrm{m}^{3}\right)\end{array}$ & & $\begin{aligned} \mathrm{U} 1 & =\mathrm{i} / \mathrm{k} \\
\mathrm{U} 2 & =\mathrm{j} / \mathrm{m} \\
\mathrm{U} 3 & =1 / \mathrm{p} \\
\mathrm{U} 4 & =\mathrm{m} / \mathrm{i}\end{aligned}$ \\
\hline Environment (E) & $\begin{array}{l}\text { E1: \% pollution of surface water } \\
\text { E2: \% groundwater supply }\end{array}$ & & $\begin{array}{l}\mathrm{E} 1=\mathrm{n} / \mathrm{e} \\
\mathrm{E} 2=\mathrm{o} / \mathrm{k}\end{array}$ \\
\hline
\end{tabular}




\section{Results}

In this section, the spatio-temporal changes in Water Poverty Index (WPI) and its sub-components for the three inland river basins in the Hexi Corridor are presented. For an easy interpretation, the results are discussed in three distinct parts: firstly, the temporal variations of the WPI components and their comparisons among the three basins are made; secondly, the temporal variations of the water poverty situation are studied; and, thirdly, a comparison of the components, WPI, and its spatio-temporal variations in selected lower and upper bound years (2003 and 2015) are presented.

\subsection{Temporal Variation of the Components and Comparisons made among Basins}

Figure 2 shows the temporal variation of water stress components (i.e., Resources, Access, Capacity, Use, and Environment) applied to determine the value of WPI for SLRB, HHRB, and SYRB from 2003 to 2015. It is noteworthy that the overall trends found in the four components followed a distinct pattern, both in terms of their magnitude (and thus their effects on water stress situations) and their actual dynamics over the study period. In greater detail, the changes in various components are described as follows.

- $\quad$ Resources component: Based on Figure 2a, the water resources conditions in SLRB are better than in the other basins. In contrast, the SYRB represents a disastrous situation in terms of water resources. SLRB shows that the range between the highest and the lowest value was about 1.2; this indicates a stable water situation, especially in respect to the range found for both HHRB and SYRB, which attained values of 33.7 and 26.5, respectively. For HHRB, the resource component appears to fluctuate significantly and shows two periods of relatively high scores (>41) for 2005-2006 and 2008-2012. However, the graph also shows that the availability of water has been declining after a peak value found in 2009. In SYRB, the changes appear to occur in two stages; one that shows a decreasing stage (2003-2008), and the other a slight increasing stage (2008-2015). However the values of the first stage are higher than the later stage.

- Access component: The access component (Figure 2b), representing infrastructure to access water resources, stands at odds with the resources component, for which HHRB reveals the best water condition. Except for 2008, the index remains remained persistently higher than the SLRB. Interestingly, there is a decline after the year 2012. For the SYRB, this component shows an increase especially after the year 2009, with a dramatic rise in the score from 2009 (=8.6) to 53.1 in 2015. It is also noticeable that the curve for SLRB rises before the year 2008, but it exhibits a steep decline afterwards. This suggests that the infrastructure conditions in SYRB are improving more than in a trend noted for SLRB.

- Capacity component: The capacity to access water resources, as shown in Figure 2c, appears to be increasing on a year to year basis at least up till the year 2013. Interestingly, after the year 2013, the growth of this component for HHRB and SYRB became slower in terms of the change in the gradient of the line. Overall, in terms of the lowest to the highest value for the basins, the trend follows SLRB > HHRB > SYRB, indicating that SLRB has the largest while SYRB has the smallest capacity to access the water resources.

- Use component: Figure 2d shows the utilization (usage) of water resources, whereby the SYRB has the highest level and the greatest efficiency of water use. As such, the values for this component registered an increase of 25.3 during the present study period. In fact, HHRB shows the fastest-growing trend during the period 2005 to 2012 compared to the other study basins, although this appeared to fall rapidly after the year 2012. For SLRB, this component was relative higher in first two years, although its value declined and remained persistently low after the year 2004. This result indicates that better water utilization plans should be implemented in this basin to reduce the proportion of agricultural water resource consumption and, consequently, to increase the water use efficiency in the SLRB. 
- Environment component: In this component, significant differences in the pollution of the surface water and the groundwater supply can be noted among the three study basins. From the changes in Figure 2e, we note that the environmental integrity in the SLRB appears to be the best since the score is the highest compared to the other components. However, the scores for the HHRB are generally better than those for the SYRB, except for the year 2012 when they were almost at par. It is important to note that, for HHRB, environmental pressure can be seen to fluctuate significantly. In fact, the changing processes driving this component in the SYRB appeared to be similar to its resources component (Figure 2a) that has two stages; one that is a decreasing phase (2003-2008) and the other that is a slightly increasing phase (2008-2015).

(a)

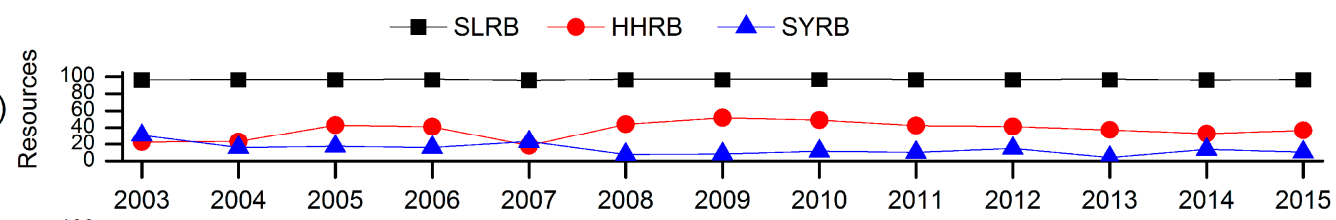

(b)

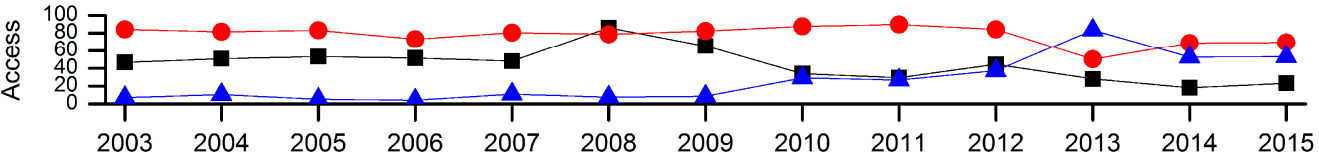

(c)

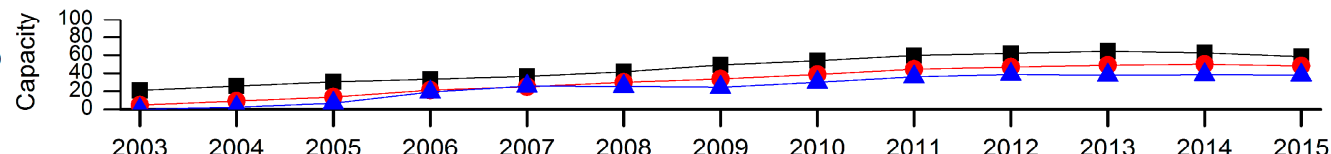

(d) $\stackrel{\oplus}{\supset}$

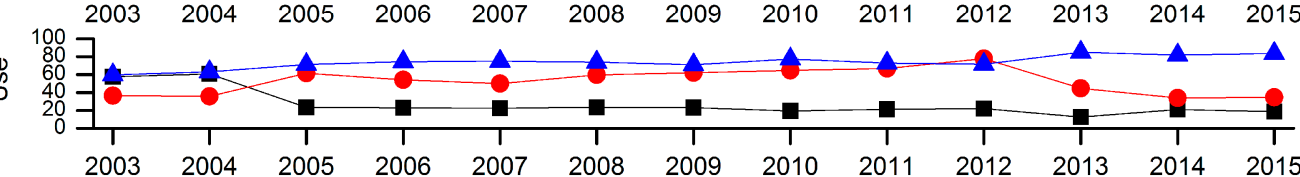

(e)

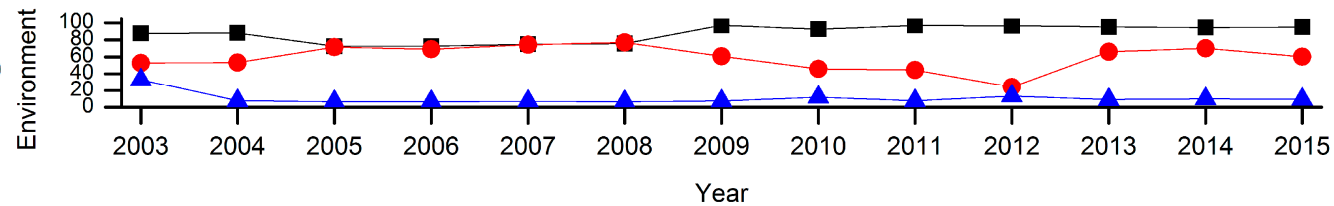

Figure 2. Trends of (a) Resource; (b) Access; (c) Capacity; (d) Use; and (e) Environment from 2003 to 2015.

\subsection{Temporal Variations of Water Poverty Situation}

The scores of the WPI and the water poverty situation are shown in Table 4 and Figure 3 . The basin with the best water situation is the SLRB, which exhibits the lowest and the highest value of WPI over the period of study; 55.3 and 66.4, respectively. This basin also shows a row of four years marked in the 'safe', six years in the 'medium safe', three years in the 'low safe', and zero years in the 'unsafe' range compared to the standard of 140 nations determined by the Center for Ecology and Hydrology (CEH) [20]. Interestingly, this basin achieved WPI values that were 10 times 'greater' than the WPI values for China. Notably, the HHRB ranks in the second place, where the WPI values fall into the range of 40.1 and 58.2. This basin also ranks itself in a relatively better water situation, especially for the period 2008-2012 compared to both standards [20]. In contrast, the WPI values for the SYRB are significantly low since the highest value is only 43.9 , which can be considered quite unsafe in water situations compared to both standards. 
Table 4. Comparison of the scores of WPI in the basins with two selected standards.

\begin{tabular}{|c|c|c|c|c|c|c|c|c|c|}
\hline Year & WPI of SLRB & $\begin{array}{l}\text { Compare to the } \\
\text { Safe Value }\end{array}$ & $\begin{array}{c}\text { Compare to WPI of } \\
\text { China }(48 \leq \text { WPI }<56)\end{array}$ & WPI of HHRB & $\begin{array}{l}\text { Compare to the } \\
\text { Safe Value }\end{array}$ & $\begin{array}{l}\text { Compare to WPI of } \\
\text { China }(48 \leq \text { WPI }<56)\end{array}$ & WPI of SYRB & $\begin{array}{l}\text { Compare to the } \\
\text { Safe Value }\end{array}$ & $\begin{array}{c}\text { Compare to WPI of } \\
\text { China }(48 \leq \text { WPI }<56)\end{array}$ \\
\hline 2003 & 61.9 & medium safe & greater & 40.2 & unsafe & less & 26.0 & unsafe & less \\
\hline 2004 & 64.4 & safe & greater & 40.6 & unsafe & less & 20.0 & unsafe & less \\
\hline 2005 & 55.3 & low safe & equal & 54.6 & low safe & equal & 21.5 & unsafe & less \\
\hline 2006 & 55.5 & low safe & equal & 51.8 & low safe & equal & 24.2 & unsafe & less \\
\hline 2007 & 55.7 & low safe & equal & 49.6 & low safe & equal & 28.4 & unsafe & less \\
\hline 2008 & 64.8 & safe & greater & 58.0 & medium safe & greater & 24.3 & unsafe & less \\
\hline 2009 & 66.4 & safe & greater & 58.2 & medium safe & greater & 24.0 & unsafe & less \\
\hline 2010 & 59.4 & medium safe & greater & 57.2 & medium safe & greater & 32.0 & unsafe & less \\
\hline 2011 & 60.8 & medium safe & greater & 57.6 & medium safe & greater & 30.7 & unsafe & less \\
\hline 2012 & 64.4 & safe & greater & 55.0 & low safe & equal & 35.1 & unsafe & less \\
\hline 2013 & 59.5 & medium safe & greater & 49.5 & low safe & equal & 43.9 & unsafe & less \\
\hline 2014 & 58.5 & medium safe & greater & 51.2 & low safe & equal & 39.4 & unsafe & less \\
\hline 2015 & 58.4 & medium safe & greater & 49.8 & low safe & equal & 39.0 & unsafe & less \\
\hline
\end{tabular}

Note: the water resources safe value is based on the standard of 140 nations, which was determined by the Center for Ecology and Hydrology (CEH): Safe (WPI $\geq 62)$; medium safe $(56 \leq$ WPI $<62)$; low safe $(48 \leq$ WPI $<56)$; and unsafe (WPI < 48). The WPI value of China is calculated by the CEH. Figure 3 shows the temporal trends in the Water Poverty Index over the study period 2003-2015. Notably, the WPI values for both the SYRB and HHRB show an upward trend over the entire period of study such that the scores of WPI for the SYRB appeared to increase more rapidly, while those for the SLRB appeared to exhibit a slightly decreasing trend. This indicates that the water situation has indeed improved more effectively in the HHRB and especially in the case of the SYRB. 


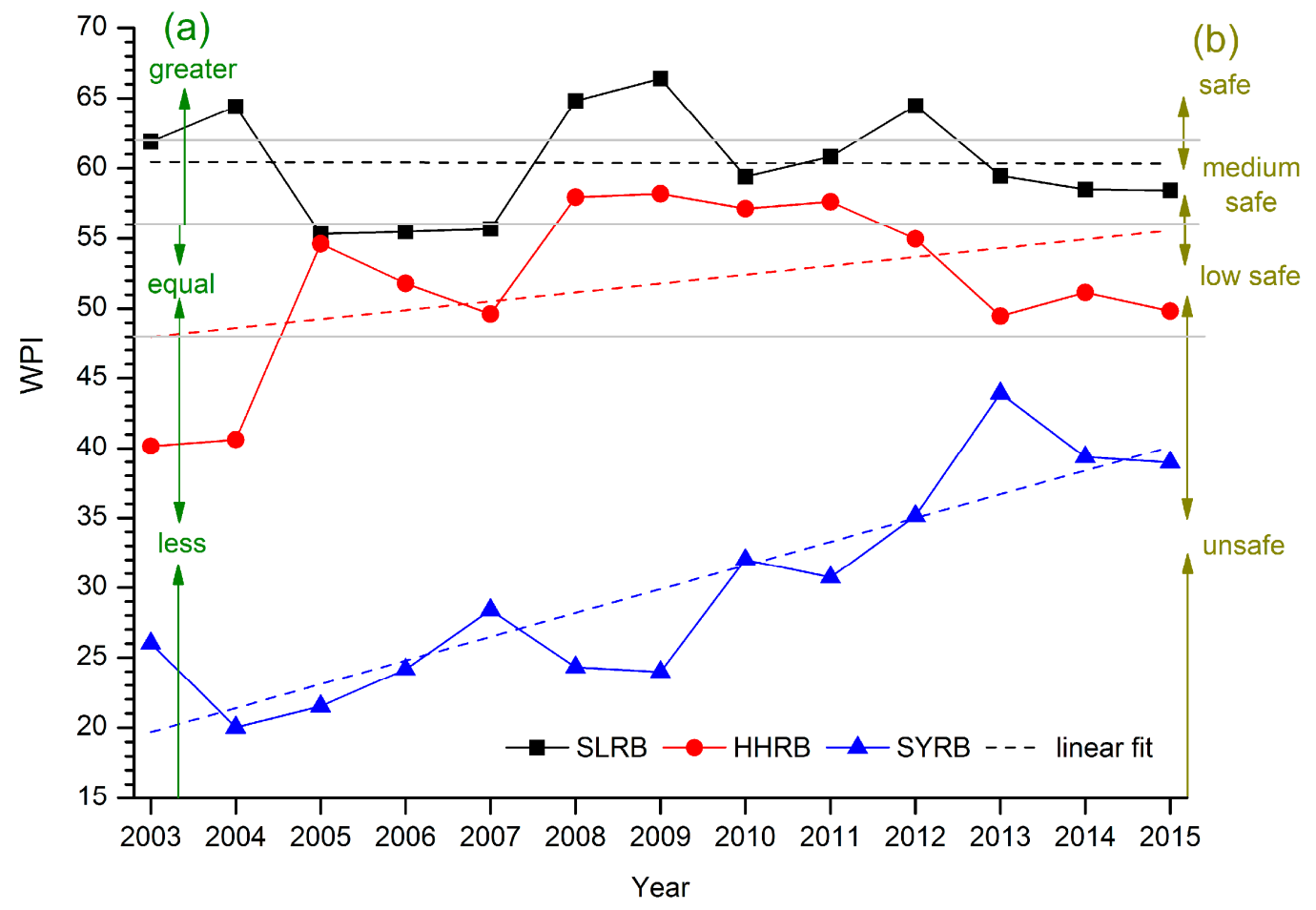

Figure 3. Trends of Water Poverty Index (WPI) (a) among the basins from 2003 to 2015 and the WPI values compared to the standards of China and (b) for the 140 nations.

\subsection{Spatio-Temporal Changes in WPI and the Components}

In this paper, we employed pentagrams to analyze the spatio-temporal variation in WPI and the water components within the study basins. Figure 4 shows a pentagram diagram with WPI indicating its merits and weaknesses and the changes for the year 2003 and 2015. In accordance with the WPI, the SLRB exhibits the best water situation while the SYRB exhibits the worst. While the WPI score for the SYRB exhibits the greatest increase, attaining a value of 13 , that for the HHRB exhibits an increase of 9.6, and that for SLRB exhibits a decrease of 3.5. This shows clearly that more stringent water policy measures are necessary to address the water poverty situation in the SLRB compared to the other counterparts.

From the components of the WPI in each basin considered in the Hexi Corridor, we can see that the contribution orders to the WPI for the SLRB, HHRB and SYRB in 2003 followed the sequence R > E $>\mathrm{U}>\mathrm{A}>\mathrm{C}, \mathrm{A}>\mathrm{E}>\mathrm{U}>\mathrm{R}>\mathrm{C}$, and $\mathrm{U}>\mathrm{E}>\mathrm{R}>\mathrm{A}>\mathrm{C}$, respectively, while the contribution orders for 2015 followed the sequence $\mathrm{R}>\mathrm{E}>\mathrm{C}>\mathrm{A}>\mathrm{U}, \mathrm{A}>\mathrm{E}>\mathrm{C}>\mathrm{R}>\mathrm{U}$, and $\mathrm{U}>\mathrm{A}>\mathrm{C}>\mathrm{R}>\mathrm{E}$, respectively. This sequencing indicates that, in the SLRB, the Resources and Environment constitute the majority of the contributions to the WPI. However, the scores of Capacity appeared to increase by 37.3, while Use shows a decrease of 38.9, and Access shows a relatively low value compared to the others.

In the HHRB, the results showed that Access and Environment constitute the majority of the contributions to the WPI. Importantly, the scores for Capacity appeared to increase with the largest margin to a value of 42.5. In the SYRB, Use has a relatively high score, and the contributions of Use, Access, and Capacity appeared to increase rapidly, while Resources and Environment appeared to decrease. In addition, the HHRB appeared to have the most balanced situation of the water resource components in the year 2015 since the differences among the components are were not so distinct. 

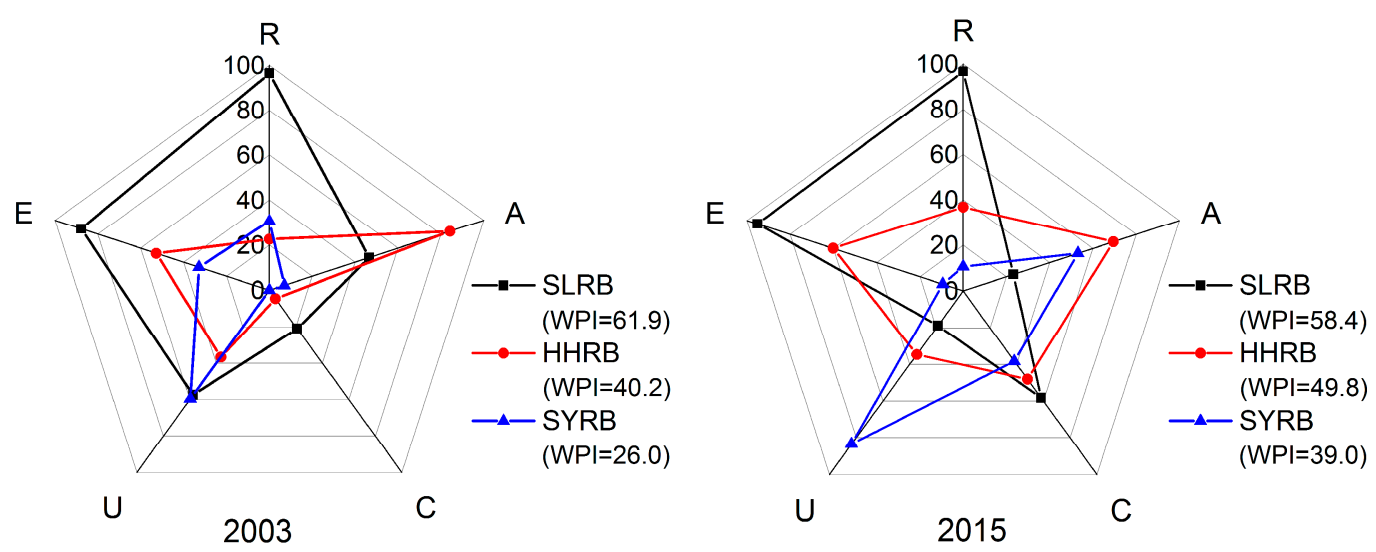

Figure 4. Pentagrams of WPI and various components ( $\mathrm{R}=$ Resource; $\mathrm{A}=$ Access; $\mathrm{C}=$ Capacity; $\mathrm{U}=\mathrm{Use} ; \mathrm{E}=$ Environment) in the three basins for the start (2003) and end (2015) period.

\section{Discussion}

\subsection{Outcomes of Polices on Settling Water Poverty}

Policy plays a very important role in natural resources management (including water) as it can lay out a government's framework for guiding key strategic decisions [33]. It was through a series of policy reforms that about $7.5 \times 10^{4}$ peasantry were resettled in the SLRB region: reservoirs, trunks, and branches were built; irrigated land was expanded; and saline-alkali land was improved in the SLRB when the Inhabitant Resettlement Project was passed in 2007 [34]. Importantly, these events led to an increase in the magnitude of A1, A2, U1, and E2 (Table 3), which produced a direct influence on the Access and Use components and an indirect influence on the Environment component. As a result of this, the graph showing the Access component displayed an increasing trend and retained relatively high scores, while the graph for the Environment component showed a decline before the year 2008 and that for the Use component showed a decline and retained relatively lower scores until the year 2015.

It is pertinent to note that a large number of peasantry migrations to the SLRB region contributed to a greater consumption of resources, which in fact led to a slightly decreasing trend in the WPI to for the SLRB, despite some counteractive measures being implemented. In the HHRB, the preliminary framework of the water-saving society operation mechanism was also formed, and the economic growth rate increased in Zhangye city. Consequently, the area of river without water downstream decreased; the areas of desertification and salinization have decreased [35]; and water began to flow into the Juyan Lake, the terminal lake of HHRB, after almost 42 years of the lake being dried out [36]. In concurrence with these changes, it is envisaged that the Water Poverty Index can be applied to show the water status on any given basin scale. In the SYRB, cropland and wasteland were converted to forest and grassland, the total amount of water consumption and agricultural water consumption reduced, and the ratio of domestic, ecological, industrial, and agriculture water was adjusted to 5.2:14.6:8.5:71.7 from about 2.7:2.9:6.6:87.8. Moreover, the income of the farmers was increased, the groundwater exploitation decreased, and the groundwater level of the terminal lake rose [37]. Consequently, the projects implemented in this region led to a more rapid increase in the scores of the WPI for the SYRB.

In this paper, a major outcome was the spatio-temporal analysis of the Water Poverty Index (WPI) applied to test its performance over three basins. The analysis clearly revealed the impact of water management plans and related projects that appear to have improved the water situations in the SYRB and HHRB to a larger extent compared to a lesser impact on the SLRB. In light of this study, it is construed that better plans for a reduction in water stress in the SLRB are needed. From a practical perspective, it is envisaged that the WPI can provide effective guidance for water resources management and priorities for a study region. This was evident, for example, in this 
study where future water-related policies should perhaps focus on the three basins as a priority in a decreasing order of importance with the SYRB at the highest, the HHRB at the mid, and the SLRB at the lowest rank. Importantly, the sub-components of the WPI can help prioritize the basin on which to focus. For example, better performance of water plans in the SYRB related to the 'Access' and 'Capacity' components of the WPI were found, whereas the performance of the 'Resources' and 'Environment' components appeared to lag behind. That indicates that the cause of environmental problems (e.g., discharge of wastewater and groundwater exploitation) should also be considered a priority in the future.

\subsection{Issues and Challenges of WPI used to Assess Water Stress and Water Management Polices}

For the first time in this study region, the WPI was constructed and applied to provide a greater understanding of the links between the physical extent of water availability and the eco-environment, including its effects on economics, politics, and the level of societal welfare for studying the water stress situation. The findings have significant implications for water resources management and the necessary future research to be performed in these basins. The benefits of the WPI are far reaching as they do not only show the efficacy of previous water management plans and the sustainability of the projects but also that the index is useful for prioritizing the needs of the study basins in terms of the required improvements in the water situation in the future.

The present study also offered a pragmatic way to evaluate the water poverty situation in the Hexi Corridor of northwest China, where increasing water pressures have received much attention over a long period of time. In response to developing water management measures, the study of Xiao et al. [31] developed the Water Security Model, while the study of Zhang et al. [30] chose the WPI to assess a water stress situation. The former study found that the level of water pressure was the highest in the Shiyang River Basin, followed by the Heihe and Shule River Basins. A study by Chen et al. [38] used the WPI framework to calculate the water poverty index for the Shiyang watershed region from 2001 to 2010, showing a weakening tendency of water pressures. Kharrazi et al. [17] indicated that the efficiency of the ecosystem water services of the middle reaches of the Heihe River Basin has increased from 2000 to 2009 through Ecological Network Analysis. Though different indicators or models were chosen, the present research paper on water pressure rankings in the three basins and trends in the WPI for the SYRB are consistent with previous research works. However, in previous studies, there was an ambiguity over the change of the water situation in terms of the passage of time and water management policy implementations. Therefore, this study has facilitated a more comprehensive evaluation of the water pressures based on five primary components and the sub-components considered in the computation of the WPI.

It should also be noted that, in this work, we demonstrated the efficacy of the WPI for inland river basins located in the Hexi corridor. However, there are some limitations. For example, a selection of variables, weighting schemes, and aggregation methods for computing the index $[8,14,17]$ could be considered in a different manner in a separate study. Among these challenges are also the issue of data limitation and data quality in different study regions [39] as the data collected can be subject to regional and institutional politics [14]. According to Sullivan et al. [14], a better way of using this index is to seek more official data so that the approach can address data scarcity issues, particularly in developing countries $[17,40]$. Therefore, in this work, we collected the key indicators from the Water Resources Bulletin in the Gansu Province, which is authentic data published by the Water Administrative Departments starting in the year 2003 (i.e., the start of our study period). In our paper, the data were mainly collected from the Water Administrative Departments and Statistical Bureau, supplemented by typical surveys, sampling surveys, and cross-checks from top-down and bottom-up perspectives, which were then compiled and adjusted according to the National Water Resources Comprehensive Planning (2003), Technology Detailed Rules of the National Integrated Water Resources Planning (2005), and the Code of Practice for the Water Resources Bulletin (2009). The former was adopted to include the data statistics of the basin scale. It is also acknowledged 
that, at the basin scale, some of the indicators of water stress and water use are difficult to acquire; for example, the mortality rates of the population under five, the educational level of the population, and so on. We, therefore, have applied only the Gross Domestic Product (GDP) per capita as the Capacity component in this paper. In spite of the rigorous testing of the hypothesis, the official data are prone to many issues of definition, agency bias, and statistical error [41] and the index and the data may not reveal the true degree of water poverty [14]. However, this study does indicate to a credible extent the degree of water resources conditions in the basins and the achievement of water management strategies applied over the historical period of study.

In the context of this paper, we have used the Water Poverty Index as a normalized statistical metric as an important tool to assist natural resource managers in decision-making process and thus to help facilitate plans and response measures. Alternative research works with different methods can also be performed to provide in-depth assessments of water poverty. For example, the application of artificial neural networks (ANNs) has been used to evaluate the hydrological consequences of climatic situations in terms of the probability of demand failure in a water resources system in the Guadalquivir River Basin, southern Spain [42]. ANNs have also been used to identify maps of the probabilities of drought occurrences in Portugal [43], while a multi-objective optimization model has been applied for rural water supply systems in Cuiabá, Brazil [44]. In other studies, the envision rating system was used to assess the sustainability of groundwater infrastructure to address concerns for water supply [45]. These studies can provide robust alternative ways to investigate the sustainability of projects and water management decisions, including water poverty for integrated planning and water resources management; however, this was outside the scope of the present research and, therefore, awaits another independent study.

\section{Conclusions}

In order to evaluate water stress and management plans in the inland river basins of the Hexi Corridor, China for the period 2003 to 2015, several indicators coupled with physical, social, political, and economic aspects of water stress were selected to comprehensively assess the water poverty situation and temporal variations based on the Water Poverty Index (WPI). The primary conclusions of this work are as follows.

From various components and trends based on pentagram diagrams for the study basins, we conclude that the SLRB showed the best water resource availability conditions, with the highest capacity to access the water resources with the lowest environmental pressures. However, it was also evident that this basin exhibited a relative deficiency in the distribution of water resources in various water sectors, with a notable degree of inefficiency of water use. For the HHRB, the study found a better infrastructure that was available to access the water resources, including an equilibrium development among the five components. In contrast to these two basins, the SYRB demonstrated the highest utilization of water resources, which was also characterized by an extreme lack of water and a disastrous environmental impact. In accordance with this finding, the components 'Use' and 'Access' in the SLRB, 'Use' and 'Resource' in the HHRB, and 'Resources' and 'Environment' in the SYRB should be given significant priority for each study basin.

According to the magnitude of the WPI and its comparison with the standard values, the ranking of water shortage in terms of the extremities from the lowest to the most serious category for the basins was found to be in the order of the SLRB, followed by the HHRB and then the SYRB, which appeared to be consistent with the reality in these regions. It is therefore recommended that the development of a water situation guideline by decision-makers should be consistent with the water stress situations based on the WPI. The trends found for the WPI for the period 2003 to 2015 showed that integrated policies and water-stress plans in SYRB were the most effective, with WPI values ranging from 26 in 2003 to 39 in 2015. In other words, the water situation of this area has improved over the study period. In contrast, the HHRB yielded WPI scores that increased by 9.6, whereas the water situation in the 
SLRB showed that the index had decreased slightly by 3.5. Clearly, better management strategies and water plans are required for the SLRB in the future.

In summary, we aver that policies, strategies, and work plans implemented in the inland river basins can mainly be devised for improving the deteriorating conditions of the ecological environment in the lower reaches of the basins (including the upstream and midstream areas). These notable effects are the result of substantial policy effects and those that may not be captured adequately by presenting aggregate statistics at the river basin scale. Thus, future studies based on the Water Poverty Index should be performed in the relevant sub-basins, particularly to discuss in a more comprehensive way the water situation and the general trends in water poverty among the upper, middle, and downstream regions of each basin along with an assessment of the comprehensive management plans that may have been launched.

Acknowledgments: This work was supported by the National Natural Science Foundation of China (No. 31370466 and 41601036) and the Key Research Program of the Chinese Academy of Sciences (KZZD-EW-04-05). Ravinesh C. Deo thanks the CAS Presidential International Fellowship Initiative Program and USQ Academic Development and Outside Studies (ADOSP, 2016) grant that facilitated collaboration with CAS scientists in China. We thank the Hydrology and Water Resources Bureau of Gansu Province for providing data. We thank all reviewers whose comments have improved the clarity of the paper.

Author Contributions: Shan Huang, Qi Feng, and Zhixiang Lu conceived and designed the approach to this article; Shan Huang analyzed the data and wrote the first draft of the manuscript; and Xiaohu Wen and Ravinesh C. Deo edited to improve the draft and the final manuscript.

Conflicts of Interest: The authors declare no conflict of interest.

\section{References}

1. Brack, W.; Dulio, V.; Agerstrand, M.; Allan, I. Towards the review of the European Union Water Framework management of chemical contamination in European surface water resources. Sci. Total Environ. 2017, 576, 720-737. [CrossRef] [PubMed]

2. Rijsberman, F. Can develpoment of water resources reduce poverty. Water Policy 2003, 5, 399-412.

3. Wilk, J.; Jonsson, A.C. From water poverty to water prosperity-A more participatory approach to studying local water resources management. Water Resour. Manag. 2013, 27, 695-713. [CrossRef]

4. Iglesias, A.; Quiroga, S.; Moneo, M.; Garrote, L. From climate change impacts to the development of adaptation strategies: Challenges for agriculture in Europe. Clim. Chang. 2012, 112, 143-168. [CrossRef]

5. Ludwig, R.; Roson, R.; Zografos, C.; Kallis, G. Towards an inter-disciplinary research agenda on climate change, water and security in Southern Europe and neighboring countries. Environ. Sci. Policy 2011, 14, 794-803. [CrossRef]

6. Milano, M.; Reynard, E.; Koplin, N.; Weingartner, R. Climatic and anthropogenic changes in Western Switzerland: Impacts on water stress. Sci. Total Environ. 2015, 536, 12-24. [CrossRef] [PubMed]

7. Kharrazi, A.; Akiyama, T.; Yu, Y.; Li, J. Evaluating the evolution of the Heihe River basin using the ecological network analysis: Efficiency, resilience, and implications for water resource management policy. Sci. Total Environ. 2016, 572, 688-696. [CrossRef] [PubMed]

8. Jemmali, H.; Abu-Ghunmi, L. Multidimensional analysis of the water-poverty nexus using a modified Water Poverty Index: A case study from Jordan. Water Policy 2016, 18, 826-843. [CrossRef]

9. El-Gafy, E.D. The water poverty index as an assistant tool for drawing strategies of the Egyptian water sector. Ain Shams Eng. J. 2015. [CrossRef]

10. Lawrence, P.; Meigh, J.; Sullivan, C. The Water Poverty Index: An international Comparison; Keele Economics Research Papers; Keele University: Newcastle, UK, 2002; pp. 1-24.

11. Pandey, V.P.; Manandhar, S.; Kazama, F. Water poverty situation of Medium-sized River Basins in Nepal. Water Resour. Manag. 2012, 26, 2475-2489. [CrossRef]

12. Pires, A.; Morato, J.; Peixoto, H.; Botero, V.; Zuluaga, L.; Figueroa, A. Sustainability assessment of indicators for integrated water resources management. Sci. Total Environ. 2017, 578, 139-147. [CrossRef] [PubMed]

13. Sullivan, C.A. Calculating a Water Poverty Index. World Dev. 2002, 30, 1195-1210. [CrossRef]

14. Sullivan, C.A.; Meigh, J.R.; Giacomello, A.M. The Water Poverty Index: Development and application at the community scale. Nat. Resour. Forum 2003, 27, 189-199. [CrossRef] 
15. Heidecke, C. Development and Evaluation of a Regional Water Poverty Index for Benin; International Food Policy Research Institute (IFPRI): Washingtion, DC, USA, 2006; pp. 1-55.

16. Sullivan, C.A.; Meigh, J. Integration of the biophysical and social sciences using an indicator approach: Addressing water problems at different scales. Water Resour. Manag. 2007, 21, 111-128. [CrossRef]

17. Kini, J. Inclusive Water Poverty Index: A new tool for helping local water and sanitation services planning. Water Policy 2016. [CrossRef]

18. Dickson, S.E.; Schuster-Wallace, C.J.; Newton, J.J. Water security assessment indicators: The rural context. Water Resour. Manag. 2016, 30, 1567-1604. [CrossRef]

19. Pérez-Foguet, A.; Garriga, G.R. Analyzing Water Poverty in Basins. Water Resour. Manag. 2011, 25, $3595-3612$. [CrossRef]

20. Li, X.; Wan, J.; Jia, J.L. Application of the Water Poverty Index at the districts of Yellow River Basin. Adv. Mater. Res. 2011, 250-253, 3469-3474. [CrossRef]

21. Van Ty, T.; Sunada, K.; Ichikawa, Y.; Oishi, S. Evaluation of the state of water resources using Modified Water Poverty Index: A case study in the Srepok River basin, Vietnam-Cambodia. Int. J. River Basin Manag. 2010, 8, 305-317. [CrossRef]

22. Mogheir, Y.; Aiash, M. Evaluation of Gaza Strip water situation and Water National Plans using international Water Poverty Index (WPI). Int. J. Emerg. Tech. Adv. Eng. 2013, 3, 396-404.

23. Manandhar, S.; Pandey, V.P.; Kazama, F. Application of Water Poverty Index (WPI) in Nepalese Context: A case study of Kali Gandaki River Basin (KGRB). Water Resour. Manag. 2012, 26, 89-107. [CrossRef]

24. Jemmali, H.; Sullivan, C.A. Multidimensional analysis of water poverty in MENA Region: An empirical comparison with physical indicators. Soc. Indic. Res. 2014, 115, 253-277. [CrossRef]

25. Franks, T.; Cleaver, F. Water governance and poverty: A framework for analysis. Progr. Dev. Stud. 2007, 291-306. [CrossRef]

26. Mlote, S.D.M.; Sullivan, C.; Meigh, J. Water Poverty Index: A tool for integrated water managemen, Water Demand Management for Sustainable Development. In Proceedings of the 3rd Conference on Symposium, Dar es Salaam, Tanzania, 30-31 October 2002.

27. Vyver, C. Water Poverty Index Calculation: Additive or multiplicative function? J. S. Afr. Bus. Res. 2013, 1-11. [CrossRef]

28. Sullivan, C.; Meigh, J.; Lawrence, P. Application of the Water Poverty Index at different scales: A cautionary tale. Water Int. 2006, 31, 412-426. [CrossRef]

29. Pan, Y.H.; Gu, C.J.; Ma, J.Z.; Zhang, T.S.; Zhang, H. Water Poverty Index in the inland river basins of Hexi Corridor, Gansu province. Adv. Mater. Res. 2014, 864-867, 2371-2375. [CrossRef]

30. Zhang, H.; Ding, J.F.; Wang, J.F. Application of Water Poverty Index at three inland river basins in Hexi Corridor. Yellow River 2012, 34, 42-44. (In Chinese).

31. Xiao, S.C.; Li, J.X.; Xiao, H.L.; Liu, F.M. Comprehensive assessment of water security for inland watersheds in the Hexi Corridor, Northwest China. Environ. Geol. 2008, 55, 369-376. [CrossRef]

32. Zhang, R.; Zhang, R.J.; Duan, Z.H.; Tan, M.L.; Chen, X.H. The assessment of water stress with the Water Poverty Index in the Shiyang River Basin in China. Environ. Earth Sci. 2012, 67, 2155-2160. [CrossRef]

33. Wang, F.; Mu, X.; Li, R.; Fleskens, L.; Stringer, L.C.; Ritsema, C.J. Co-evolution of soil and water conservation policy and human-environment linkages in the Yellow River Basin since 1949. Sci. Total Environ. 2015, 508, 166-177. [CrossRef] [PubMed]

34. Comprehensive Development Project of Agriculture Irrigation and Inhabitant Resettlement in Shule River Basin Passed the Acceptance Check of the Ministry of Environmental Protection of the People's Republic of China. Available online: http://www.gsslh.cn/lydt/lyyx/201111/3868.html (accessed on 30 November 2011).

35. Cheng, G.D.; Li, X.; Zhao, W.Z.; Xu, Z.M.; Feng, Q.; Xiao, S.C.; Xiao, H.L. Integrated study of the water-ecosystem-economy in the Heihe River Basin. Natl. Sci. Rev. 2014, 1, 413-428. [CrossRef]

36. Qiao, L.X; Shi, G.A. The implementation of unified water transfer in Heihe Basin. In China's Water Conservancy Development Report; China Water Power Press: Beijing, China, 2005.

37. Major Treatment Planning of Shiyang River Basin in Wuwei Pass the Acceptance. Available online: http: / / www.gs.xinhuanet.com/shiyanghe/2016-03/03/c_1118225596.htm (accessed on 3 March 2016).

38. Chen, L.; Shi, P.; Wei, W. Water Poverty temporal-spatial differentiation in the Shi Yang River Basin. Res. Sci. 2013, 35, 1373-1379. 
39. Gleick, P.H. On methods for assessing water-resource risks and vulnerabilities. Environ. Res. Lett. 2015, 10, 111003. [CrossRef]

40. Booysen, F. An overview and evaluation of composite indices of composite indices of development. Soc. Indic. Res. 2002, 59, 115-151. [CrossRef]

41. Nickum, J.E. Irrigated area figures as bureaucratic construction of knowledge: The case of China. Int. J. Water Resour. D 2003, 19, 249-262. [CrossRef]

42. Pulido-Calvo, I.; Gutiérrez-Estrada, J.C.; Savic, D. Heuristic modelling of the water resources management in the Guadalquivir River Basin, Southern Spain. Water Resour. Manag. 2012, 26, 185-209. [CrossRef]

43. Santos, J.; Portela, M.M.; Pulido-Calvo, I. Previsão de secas na primavera em Portugal Continental com base em indicadores climáticos de larga escala. Ing. Agua 2015, 11, 211-227. [CrossRef]

44. Silva, W.T.P.; Vieira, L.T.Q.; Rosa, D.M.S.; Campos, M.M.; Santos, A.A.; Souza, M.A.A. Otimização multiobjetivo de sistema de abastecimento de água rural. Ing. Agua 2016, 20, 217-232. [CrossRef]

45. Saville, C.R.; Miller, G.R.; Brumbelow, K. Using envision to assess the sustainability of groundwater infrastructure: A case study of the Twin Oaks Aquifer Storage and Recovery Project. Sustainability 2016, 8, 501. [CrossRef]

(C) 2017 by the authors. Licensee MDPI, Basel, Switzerland. This article is an open access article distributed under the terms and conditions of the Creative Commons Attribution (CC BY) license (http:/ / creativecommons.org/licenses/by/4.0/). 